\title{
Does post-operative radiotherapy improve the treatment outcomes of intracranial hemangiopericytoma? A retrospective study
}

Jianbiao Xiao ${ }^{1,2+}$, Lanwei Xu ${ }^{3 \dagger}$, Yi Ding ${ }^{4}$, Wei Wang ${ }^{5}$, Fen Chen ${ }^{6}$, Yangshu Zhou', Fengjiao Zhang ${ }^{8}$, Qiyuan Zhou ${ }^{6}$, Xuehui $\mathrm{Wu}^{1,2}$, Junpeng $\mathrm{Li}^{9}$, Li Liang ${ }^{1,2^{*}}$ and Yee-Min Jen ${ }^{10^{*}}$ (D)

\begin{abstract}
Background: Intracranial hemangiopericytoma is a rare disease and surgery is the mainstay treatment. Although postoperative adjuvant radiotherapy is often used, there are no reports comparing different radiotherapy techniques. The purpose of this study is to analyze the impact of post-operative radiotherapy and different radiotherapy technique on the results in patients with intracranial hemangiopericytoma (HPC).

Methods: We retrospectively reviewed 66 intracranial HPC patients treated between 1999 and 2019 including 29 with surgery followed by radiotherapy (11 with intensity-modulated radiotherapy (IMRT) and 18 with stereotactic radiosurgery (SRS)) and 37 with surgery alone. Chi-square test was used to compare the clinical characteristic between the groups. The Kaplan-Meier method was used to analyze overall survival (OS) and recurrence-free survival (RFS). Multivariate Cox proportional hazards models were used to examine prognostic factors of survival. We also underwent a matched-pair analysis by using the propensity score method.

Results: The crude local control rates were $58.6 \%$ in the surgery plus post-operative radiotherapy group (PORT) and $67.6 \%$ in the surgery alone group ( $p=0.453$ ). In the subgroup analysis of the PORT patients, local controls were $72.7 \%$ in the IMRT group and $50 \%$ in the SRS group $(p=0.228)$. The median OS in the PORT and surgery groups were 122 months and 98 months, respectively $(p=0.169)$. The median RFS was 96 months in the PORT group and 72 months in the surgery alone group $(p=0.714)$. Regarding radiotherapy technique, the median OS and RFS of the SRS group were not significantly different from those in the IMRT group $(p=0.256,0.960)$. The median RFS were 112 and 72 months for pathology grade II and III patients, respectively $(p=0.001)$. Propensity score matching did not change the observed results.
\end{abstract}

\footnotetext{
* Correspondence: redsnow007@hotmail.com; yeeminjen@chmsc.com

${ }^{\dagger}$ Jianbiao Xiao and Lanwei Xu contributed equally to this work.

'Department of Pathology, Nanfang Hospital and School of Basic Medical

Science, Southern Medical University, 1838, Guangzhoudadao Rd,

Guangzhou, Guangdong Province 510515, People's Republic of China

${ }^{10}$ Department of Radiation Oncology, Yee Zen General Hospital, 30, Yangxing

North Rd, Yang Mei District, Tao Yuan City, Taiwan

Full list of author information is available at the end of the article
}

(c) The Author(s). 2021 Open Access This article is licensed under a Creative Commons Attribution 4.0 International License, which permits use, sharing, adaptation, distribution and reproduction in any medium or format, as long as you give appropriate credit to the original author(s) and the source, provide a link to the Creative Commons licence, and indicate if changes were made. The images or other third party material in this article are included in the article's Creative Commons licence, unless indicated otherwise in a credit line to the material. If material is not included in the article's Creative Commons licence and your intended use is not permitted by statutory regulation or exceeds the permitted use, you will need to obtain permission directly from the copyright holder. To view a copy of this licence, visit http://creativecommons.org/licenses/by/4.0/ The Creative Commons Public Domain Dedication waiver (http://creativecommons.org/publicdomain/zero/1.0/) applies to the data made available in this article, unless otherwise stated in a credit line to the data. 
Conclusion: In this retrospective analysis, PORT did not improve the local control rates nor the survivals. The local control rates after IMRT and SRS were similar even though the IMRT technique had a much higher biological dose compared with the SRS technique.

Keywords: Intracranial hemangiopericytoma, Post-operative radiotherapy, stereotactic radiosurgery, Intensitymodulated radiotherapy

\section{Background}

In 1942, Stout AP and Margaret RM described a new type of vascular tumor showing the characteristic formation of endothelial tubes and sprouts surrounded by a sheath of rounded and sometimes elongated cells. They believed that these cells were derived from the capillary pericytes and suggested that the tumors be called hemangiopericytoma (HPC) [1]. In 2014, WHO reclassified hemangiopericytoma as solitary fibrous tumor [2]. From its discovery until 1954, a total of 38 cases were reported. In 1954, Begg and Garret reported the first patient of primary cranial meningeal HPC [3]. The tumor histologically resembled both the soft tissue HPC previously described by Stout and Murray and the aggressive variant of angioblastic meningioma reported by Cushing and Eisenhardt [4]. Compared to extracranial HPC, intracranial HPC is less frequent and remains a rare entity, representing $0.4 \%$ of all primary central nervous system tumors [5]; meningioma is approximately 50 to 60 times more common than intracranial HPC [6-8]. It was reported that $1.6-2.5 \%$ of tumors diagnosed as meningiomas by neuroimaging were intracranial $\operatorname{HPC}[9,10]$. The histological origin of central nervous system HPC has been controversial for a long time, and it is now widely accepted that this tumor arises from the meningeal capillary pericytes. The current WHO classification includes HPC in the group of meningeal mesenchymal non-meningothelial tumors with uncertain malignant potential or borderline malignancy [11-13].

In a study of 191 HPC patients, the authors reported that at first local recurrence, patients who underwent repeated surgery survived longer than those patients who did not (median survival time, 53.0 months vs. 35.7 months; $P=0.028$ ) [14]. In another report, postoperative radiotherapy (PORT) was shown to reduce local recurrence from $88 \%$ with surgery alone to $12.5 \%$ with PORT [15]. Kim et al. demonstrated that routine PORT with 50 to 60 Gy regardless of the resection margin and histology significantly improved the median time to local recurrence from 19.5 months in those without PORT to 80.5 months in patients with PORT $(p=0.0003)$ [16]. Some studies have suggested that complete surgical removal followed by PORT to the tumor bed is the best treatment policy for intracranial HPCs $[9,17,18]$. Others concluded that postoperative external beam radiotherapy (EBRT) to the tumor bed appears to delay recurrence $[9,17]$.
Although adjuvant radiotherapy after surgery has been frequently used in the treatment of HPC, there are no reports comparing conventionally fractionated EBRT and stereotactic radiosurgery (SRS) in HPC. The purpose of this study is to analyze the impact of PORT and different PORT techniques (conventionally fractionated EBRT versus SRS) on treatment efficacy of 66 patients with intracranial HPC.

\section{Methods \\ Patients}

This is a retrospective, observational study. The study protocol was approved by the hospital review board of the five participant hospitals. The medical charts and electronic databases of the hospitals were searched to identify patients diagnosed with primary intracranial HPC who had surgery as the first therapy between 1999 and 2019. Three patients who underwent initial surgery at other hospitals and were later treated for recurrent diseases at one of the five hospitals were also included. All of the patients had pathological confirmation of HPC. Information about their demographic data, pathology, surgery, PORT dose and technique, tumor control, survival status, and treatment-related side effects, were recorded. The pathology slides, when available, were reviewed by one of the authors to confirm the diagnosis.

One of the five participant hospitals used SRS routinely for their intracranial HPC patients. Patients from the other four hospitals were treated with conventionally fractionated intensity-modulated radiotherapy (IMRT) using linear accelerators. The patients were divided into surgery plus PORT group and surgery alone group; patients in the surgery plus PORT group were further separated into the IMRT group and the SRS group for subgroup analysis. All of the patients were evaluated clinically and radiologically with magnetic resonance imaging (MRI) scans with and without contrast. Follow-up MRI images were compared to the preoperative images by one of the authors and the tumor dimensions, if present, were measured in the axial, sagittal, and coronal planes.

\section{Statistical methods}

The primary endpoint is local tumor control, and secondary endpoints include overall and recurrence-free 
survivals. All of the statistical analyses were performed by using SPSS v.19. (SPSS Inc., Chicago, IL, USA). Mann-Whitney U-tests (two-tailed) were used to analyze the differences in continuous variables. Fisher's exact test (two-tailed) was used to examine the differences in categorical variables. Chi-squared test was conducted to compare the differences of clinical characteristics between groups. Kaplan-Meier method was applied to obtain local control, overall survival (OS) and recurrencefree survival (RFS). The outcomes were compared between those who receive and did not receive PORT and also between the IMRT and the SRS groups. Univariate and multivariate Cox proportional hazards models were used to search for potential prognostic variables including age ( $\geq 50$ years), sex, tumor location, tumor resection, pathology grade and radiation therapy.

To reduce the patient heterogeneity inherent in a retrospective study between the two groups, the $\mathrm{R}$ package "MatchIt" was used to conduct a propensity score matching. Treatment outcome analyses were repeated after 29 from the 37 surgery alone patients were matched to the 29 patients with postoperative radiotherapy. Variables matched included age, sex, tumor location, post-operative radiotherapy technique, resection extent and pathology grade.

\section{Results}

\section{Patients and radiotherapy techniques}

A total of 66 patients diagnosed with intracranial HPC were collected (Table 1). There were 35 males and 31 females with $83.3 \%$ having supratentorial lesions. Gross tumor resection (GTR) was conducted in 61 (92.4\%) and subtotal tumor resection (STR) in 5 (7.6\%) patients. Grade II HPCs were diagnosed in 35 (53\%) patients, and grade III HPCs (anaplastic HPC) were diagnosed in 31 (47\%) patients. Twenty-nine (43.9\%) patients had surgery followed by radiotherapy while 37 (56.1\%) had surgery alone. The differences in patient characteristics between the two groups with and without PORT were not statistically significant (Table 1). The median follow-up time after operation in all patients was 50.5 months (range, 2-153); it was 57 and 47 months in the surgery plus PORT and the surgery alone groups, respectively. For patients alive at the time of analysis, the median followup time was 66 months for the surgery plus PORT group and 58 months for the surgery alone group.

Of the 29 patients with PORT after operation, 11 received IMRT and 18 had SRS (12 had gamma knife SRS and 6 had linac-based SRS) (Table 2). The clinical characteristics were not significantly different between the surgery and PORT groups; they were also similar between the PORT-IMRT and the PORT-SRS groups including the extent of tumor resection and the tumor grade. Eleven patients received fractionated IMRT with a median fraction number of 30 and a median prescription dose of 60 Gy (range 50-60 Gy). IMRT was delivered with $6 \mathrm{MV}$ photons from linear accelerators (Varian Trilogy and Clinac IX; Elekta Synergy). Clinical target volume (CTV) was defined as the tumor cavity and/or

Table 1 Characteristics of 66 patients with intracranial hemangiopericytoma by the treatment types

\begin{tabular}{|c|c|c|c|c|}
\hline & All patients N (\%) & S + PORT (29 patients) N (\%) & S (37 patients) N (\%) & $P$ value \\
\hline Age in years & & & & 0.892 \\
\hline$\geq 50$ & $29(43.9 \%)$ & $13(44.8 \%)$ & $16(43.2 \%)$ & \\
\hline$<50$ & $37(56.1 \%)$ & $16(55.2 \%)$ & $21(56.8 \%)$ & \\
\hline Sex & & & & 0.493 \\
\hline Male & $35(53 \%)$ & $14(48.3 \%)$ & $21(56.8 \%)$ & \\
\hline Female & $31(47 \%)$ & $15(51.7 \%)$ & $16(43.2 \%)$ & \\
\hline Tumor location & & & & 0.579 \\
\hline Supratentorial & $55(83.3 \%)$ & $25(86.2 \%)$ & 30(81.1\%) & \\
\hline Infratentorial & $11(16.7 \%)$ & $4(13.8 \%)$ & $7(18.9 \%)$ & \\
\hline Pathology grade & & & & 0.493 \\
\hline Grade II & $35(53 \%)$ & $14(48.3 \%)$ & $21(56.8 \%)$ & \\
\hline Grade III & $31(47 \%)$ & $15(51.7 \%)$ & $16(43.2 \%)$ & \\
\hline Extent of resection & & & & 0.452 \\
\hline GTR & $61(92.4 \%)$ & 26(89.7\%) & $35(94.6 \%)$ & \\
\hline STR & $5(7.6 \%)$ & $3(10.3 \%)$ & $2(5.4 \%)$ & \\
\hline Recurrence & & & & 0.453 \\
\hline Yes & $24(36.4 \%)$ & $12(41.4 \%)$ & $12(12.4 \%)$ & \\
\hline No & $42(63.6 \%)$ & $17(58.6 \%)$ & $25(67.6 \%)$ & \\
\hline
\end{tabular}

PORT post-operative radiotherapy, S surgery, GTR gross total resection, STR subtotal resection 
Table 2 Characteristics of 29 patients with intracranial hemangiopericytoma receiving post-operative radiotherapy divided by radiotherapy technique

\begin{tabular}{|c|c|c|c|c|}
\hline & All patients $\mathrm{N}(\%)$ & IMRT (11 patients) N (\%) & SRS (18 patients) N (\%) & $P$ value \\
\hline Age in years & & & & $0.074^{*}$ \\
\hline$\geq 50$ & $13(44.8 \%)$ & $7(63.6 \%)$ & $6(33.3 \%)$ & \\
\hline$<50$ & 16(55.2\%) & $4(36.4 \%)$ & 12(66.7\%) & \\
\hline Sex & & & & 0.316 \\
\hline Male & 14(48.3\%) & $4(36.4 \%)$ & $8(55.6 \%)$ & \\
\hline Female & $15(51.7 \%)$ & $7(63.6 \%)$ & $8(44.4 \%)$ & \\
\hline Tumor location & & & & 1.000 \\
\hline Supratentorial & $25(84.2 \%)$ & $10(90.9 \%)$ & 15(83.3\%) & \\
\hline Infratentorial & $4(15.8 \%)$ & $1(9.1 \%)$ & $3(16.7 \%)$ & \\
\hline Pathology grade & & & & 0.316 \\
\hline Grade ॥ & $14(48.3 \%)$ & $4(36.4 \%)$ & $10(55.6 \%)$ & \\
\hline Grade III & $15(51.7 \%)$ & $7(63.6 \%)$ & $8(44.4 \%)$ & \\
\hline Extent of resection & & & & 0.862 \\
\hline GTR & $26(89.7 \%)$ & 10(90.9\%) & 16(88.9\%) & \\
\hline STR & $3(10.3 \%)$ & $1(9.1 \%)$ & $2(11.1 \%)$ & \\
\hline Recurrence & & & & 0.228 \\
\hline Yes & & $3(27.4 \%)$ & $9(50 \%)$ & \\
\hline No & & $8(72.7 \%)$ & $9(50 \%)$ & \\
\hline
\end{tabular}

$R T$ radiotherapy, IMRT intensity-modulated radiotherapy, SRS stereotactic radiosurgery, GTR gross total resection, STR subtotal resection

${ }^{*} P$ values are statistically significant

the residual mass plus a $5-10 \mathrm{~mm}$ margin. An additional 3-5 $\mathrm{mm}$ was added to the CTV for planning target volume. Eighteen patients underwent gamma knife SRS with a single dose of 14-16 Gy at the margin of tumor (12 had gamma knife SRS and 6 had X ray SRS) (Gamma Knife, Elekta, Perfection; Varian Clinac 23ES). Table 3 presents the characteristics of the PORT patients and the surgery alone cohort matched with the PORT patients. The differences between the two groups were not improved after propensity score matching. At the time of the study cutoff day, 24 of the 29 patients in the PORT group and 25 of 37 patients in the surgery alone group were alive. Figure 1 shows the study framework including the initial patient treatments, local recurrence and salvage therapy after local recurrence.

\section{Histological findings}

The pathological specimens with Hematoxylin \& Eosin (H\&E) staining of all the 66 patients showed an extensively vascularized and cellular tumor. These tumors showed compact and uniform cells with a large number of small vascular cavities and compact reticular fibers. Immunohistochemical (IHC) staining showed a strong positivity for CD34. The percentage of ki67 positivity was lower in grade II HPC compared with grade III tumors; the median percentage of positive staining for Ki67 was 2\% (range 1-5\%) in grade II HPC and 12\% in grade III HPC (range 10-16\%). There were more prominent nuclear fission and cell morphology heterogeneity in the higher grade $\mathrm{HPC}$. IHC was negative for PR, S100 and EM (Fig. 2).

\section{Imaging findings}

All of the patients had MRI before and after operation. After craniotomy, MRI was repeated at 3-6-month intervals in the first 3 years with and without contrast. The pre-contrast MRI showed a hypointense lesion on T1-weighted images (WI) and a heterogeneously hyperintense lesion on T2WI. A flow void signal was present in most tumor images, and cystic tumor necrosis and the dural tail sign were also very common. Contrastenhanced MRI often showed markedly and heterogeneously enhanced lesions. Fig. 2 showed one of the HPC patient' MRI images before and after operation.

\section{Local control and survival}

The crude local control rates were $58.6 \%$ in the surgery plus PORT group and $67.6 \%$ in the surgery alone group; Fig. 3A shows the local recurrence-free survival of both groups $(p=0.714)$. In the subgroup analysis of the PORT patients, they were $72.7 \%(8 / 11)$ in the IMRT group and $50 \%(9 / 18)$ in the SRS; the local-recurrence free survivals are shown in Fig. 3B $(p=0.960)$. 
Table 3 Characteristics of 58 propensity score-matched patients with intracranial hemangiopericytoma by the treatment types

\begin{tabular}{llll}
\hline & All patients N (\%) & S + PORT (29 patients) N (\%) & S (29 patients) N (\%) \\
\hline Age in years & & & \\
$\quad \geq 50$ & $24(41.4 \%)$ & $13(44.8 \%)$ & $11(37.9 \%)$ \\
$\quad<50$ & $34(58.6 \%)$ & $16(55.2 \%)$ & $18(62.1 \%)$ \\
Sex & & & \\
$\quad$ Male & $34(58.6 \%)$ & $14(48.3 \%)$ & $20(69.0 \%)$ \\
$\quad$ Female & $24(41.4 \%)$ & $15(51.7 \%)$ & $9(31.0 \%)$ \\
Tumor location & & & $24(82.8 \%)$ \\
Supratentorial & $49(84.5 \%)$ & $25(86.2 \%)$ & $5(17.2 \%)$ \\
Infratentorial & $9(15.5 \%)$ & $4(13.8 \%)$ & \\
Pathology grade & & & $20(69.0 \%)$ \\
Grade II & $34(58.6 \%)$ & $14(48.3 \%)$ & $9(31.0 \%)$ \\
Grade III & $24(41.4 \%)$ & $15(51.7 \%)$ & \\
Extent of resection & & & $29(100.0 \%)$ \\
GTR & $55(94.8 \%)$ & $26(89.7 \%)$ & 0.110 \\
STR & $3(5.2 \%)$ & $3(10.3 \%)$ & 0.110 \\
Recurrence & & & $8(27.6 \%)$ \\
Yes & $20(34.5 \%)$ & $12(41.4 \%)$ & $21(72.4 \%)$ \\
No & $38(65.5 \%)$ & $17(58.6 \%)$ & 0.075 \\
\hline
\end{tabular}

PORT post-operative radiotherapy, S surgery, GTR gross total resection, STR subtotal resection

The median RFS of grade II and III patients were 112 and 72 months, respectively $(p=0.001)$. Salvage surgery with or without PORT was conducted for most patients with local recurrence. The 5-year RFS rates in the surgery plus PORT group and surgery alone group were 56.4 and $74.6 \%$, respectively.

The median OS in the surgery plus PORT and surgery alone groups were 122 months and 98 months, respectively $(p=0.169)$ (Fig. $3 \mathrm{C})$. The median OS in the SRS and IMRT groups were 127 months and 73 months $(p=$
0.256) (Fig. 3D). The 5-year OS rates in the PORT and surgery alone groups were 75 and $90.9 \%$, respectively.

With the propensity score matching, the crude local control rates were $58.6 \%$ in the surgery plus PORT group and $72.4 \%$ in the surgery alone group. Figure $3 \mathrm{E}$ displays the local recurrence-free survival of both groups $(p=0.367)$. For the matched-pair cohort, the median OS in the surgery plus PORT and surgery alone groups were 122 months and 93 months, respectively $(p=0.159)$ (Fig. $3 \mathrm{~F}$ ); the 5 -year overall survival were $51.7 \%$ for the surgery

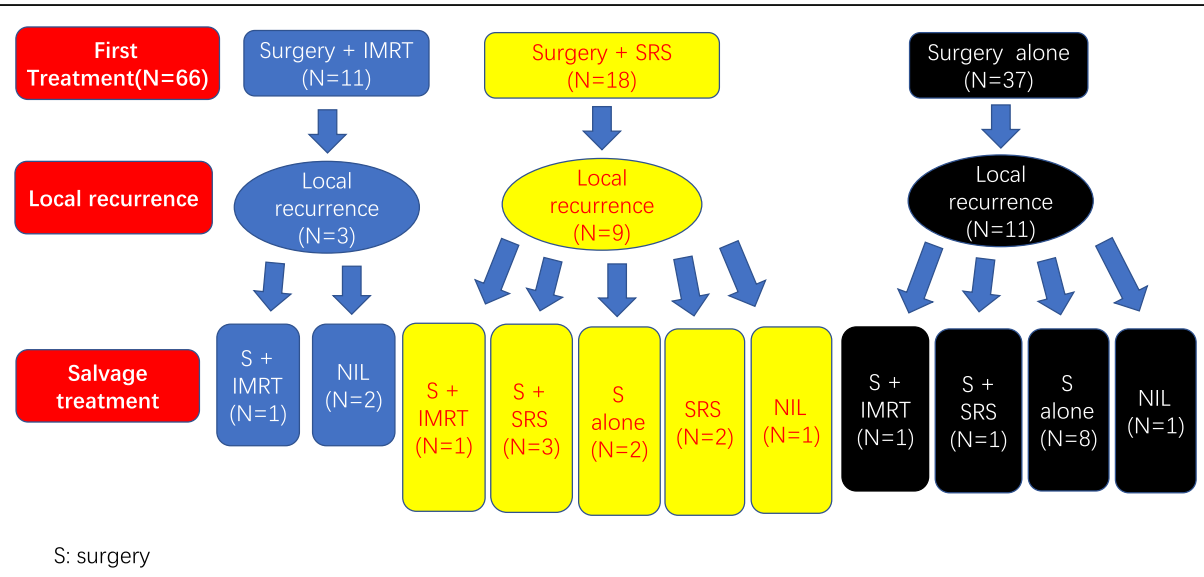

Fig. 1 A diagram showing the initial patient treatments, local recurrence and salvage therapy after local recurrence. Twenty-nine (43.9\%) patients had surgery followed by post-operative radiotherapy (PORT) while thirty-seven (56.1\%) had surgery alone. Of the 29 patients with PORT after operation, 11 received intensity-modulated radiotherapy and 18 had stereotactic radiosurgery (SRS) (12 had gamma knife SRS and 6 had linacbased SRS). There were 12 local recurrences out of the 29 patients with surgery plus PORT, and 11 of the 37 surgery alone patients 


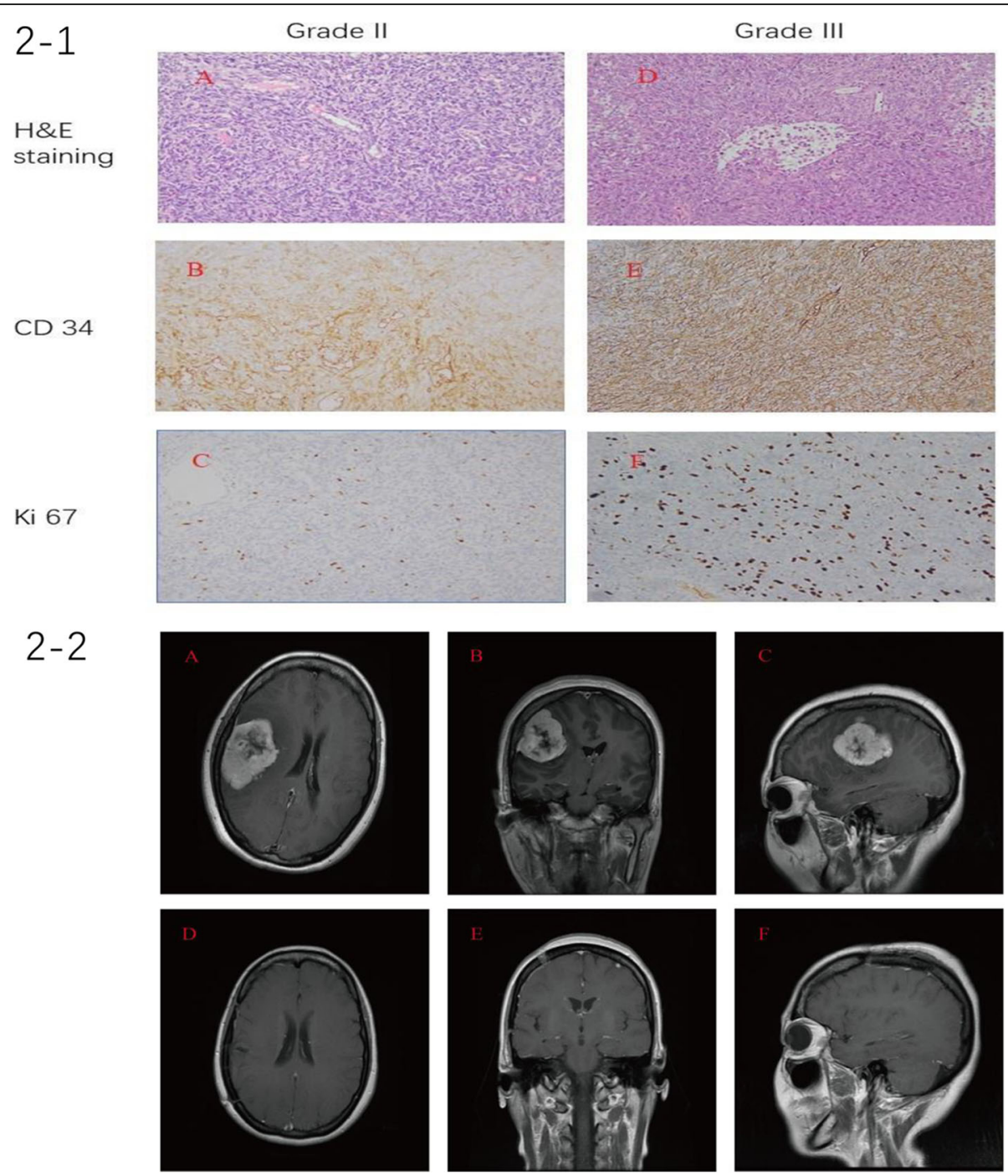

Fig. 2 Figure (2-1). A, B and C: Microphotographs of the histologic images of a grade II intracranial hemangiopericytoma patient (magnification $\times$ 200). A, Hematoxylin \& Eosin staining demonstrated an extensively vascularized and cellular tumor; $\mathbf{B}$, Immunohistochemical staining showed a strong positivity for CD34; C, immunohistochemical staining showed a 5\% positivity for Ki67; D, E and F: Microphotographs of the histologic images of a grade III intracranial hemangiopericytoma patient (magnification $\times 200$ ). D. Hematoxylin \& Eosin staining demonstrated an extensively vascularized and cellular tumor; $\mathbf{E}$, Immunohistochemical staining showed a strong positivity for CD34; F, Immunohistochemical staining showed a 10\% positivity for Ki67. Compared with grade II HPC, the grade III tumor showed a higher percentage of ki67 positivity and more prominent nuclear fission and cell morphology heterogeneity. Figure (2-2). Magnetic resonance imaging (MRI) of a grade II intracranial hemangiopericytoma patient without recurrence after gross total resection. A-C: Preoperative T1-weighted MRI scans with contrast: A axial, B coronal and C sagittal images, showing an enhanced lesion at the right temporal lobe with central necrosis. D-F Postoperative T1-weighted MRI scans with contrast: D axial, E, coronal, and $\mathbf{F}$, sagittal images, showing a complete tumor removal. The patient was recurrence-free 22 months after surgery. His histologic images were shown in Fig. 2-1

plus PORT and $34.5 \%$ for the surgery alone $(p=0.289)$. The 5 -year RFS were $65.5 \%$ for the surgery plus PORT and $82.8 \%$ for the surgery alone group $(p=0.230)$.

\section{Prognostic factors of OS and RFS}

Age $\geq 50$ years is the only prognostic factor for OS by both the univariate $(p=0.024)$ and multivariate $(p=$ 0.029) Cox regression analyses (Table 4). The median OS time is 84 months in the older group (age $\geq 50$ years) and 122 months in the younger group (age $<50$ years) $(p=0.018)$. The median RFS time is 72 months in the older group (age $\geq 50$ years) and 96 months in the younger group (age $<50$ years) $(p=0.100)$. In Table 4 , the 95\% CI for location and resection were very large. The reason is that all the 11 infratentorial patients and all the STR patients were alive and therefore censored at the time of univariate and multivariate analysis, making it impossible to obtain a statistical result. 

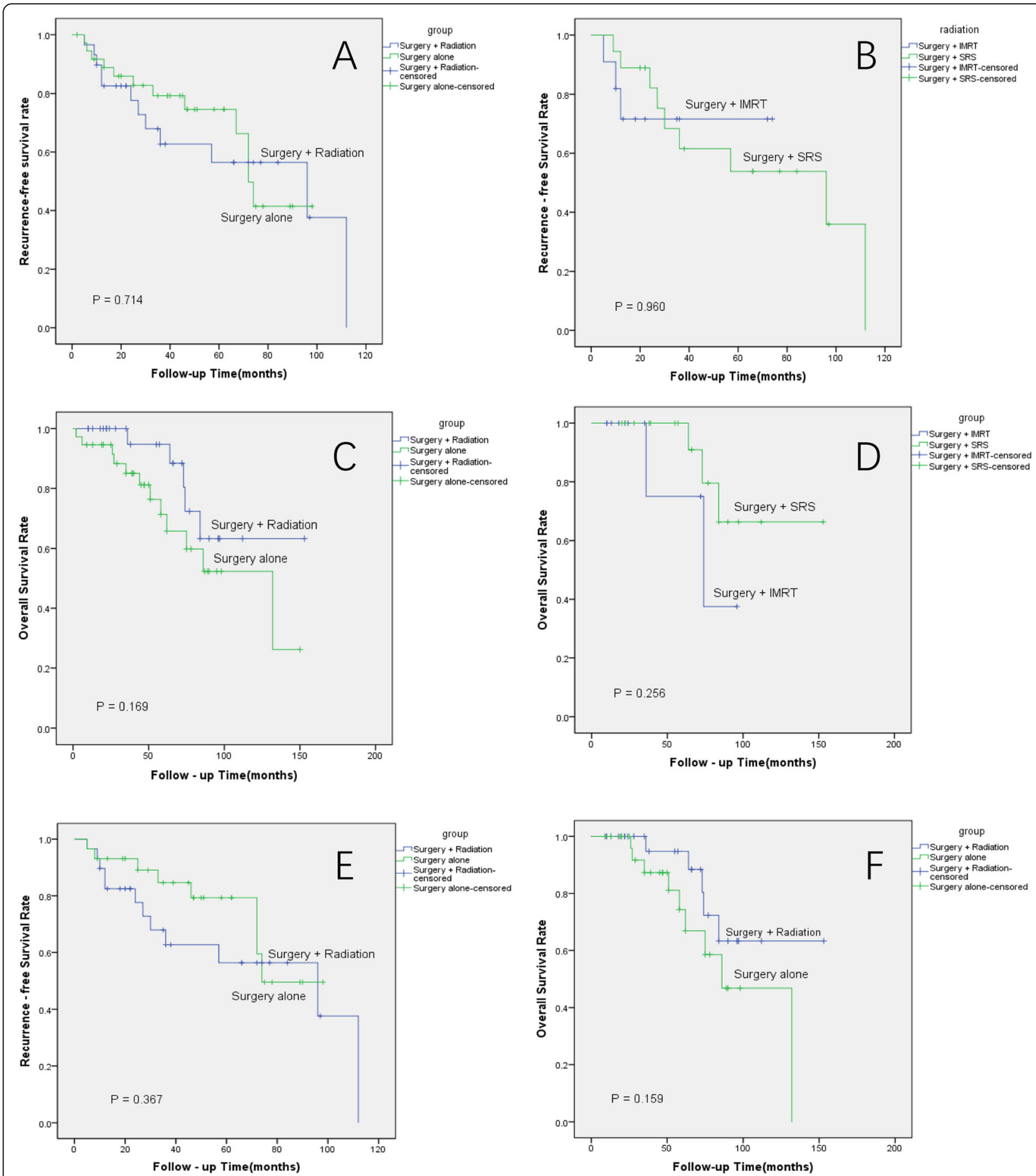

Fig. 3 A Kaplan-Meier estimates of the local recurrence-free survival (RFS) curves in intracranial hemangiopericytoma patients. Postoperative radiotherapy (PORT) did not increase the RFS $(p=0.714)$. B Kaplan-Meier estimates of the local RFS curves in intracranial hemangiopericytoma patients with PORT. The RFS of the two groups with different radiotherapy techniques were similar $(p=0.960)$. C Kaplan-Meier estimates of the overall survival (OS) curves of intracranial hemangiopericytoma patients. There were no differences between the patients with and without PORT $(p=0.169)$. D Kaplan-Meier estimates of the OS curves in intracranial hemangiopericytoma patients with PORT. The OS of the two groups were similar $(p=0.256)$. E Kaplan-Meier estimates of the recurrence-free survival curves of propensity score-matched intracranial hemangiopericytoma patients (surgery plus radiation and surgery alone groups). Postoperative radiotherapy did not increase the RFS ( $p=0.367)$. F Kaplan-Meier estimates of the overall survival curves of propensity score-matched intracranial hemangiopericytoma patients (surgery plus radiation and surgery alone groups). There were no differences between the patients with and without PORT $(p=0.159)$ 
Table 4 Univariate and Multivariate Analysis of Factors Associated with Overall Survival in Patients of Intracranial Hemangiopericytoma

\begin{tabular}{|c|c|c|c|c|}
\hline \multirow[t]{3}{*}{ Variable } & \multirow{2}{*}{\multicolumn{2}{|c|}{$\begin{array}{l}\text { Univariate Analysis } \\
\text { OS }\end{array}$}} & \multirow{2}{*}{\multicolumn{2}{|c|}{$\begin{array}{l}\text { Multivariate Analysis } \\
\text { OS }\end{array}$}} \\
\hline & & & & \\
\hline & $P$ & $95 \% \mathrm{Cl}$ & $p$ & $95 \% \mathrm{Cl}$ \\
\hline Age & $0.024^{*}$ & $0.121-0.863$ & $0.029^{*}$ & $0.103-0.883$ \\
\hline Sex & 0.282 & $0.219-1.558$ & 0.573 & $0.406-5.096$ \\
\hline Location & 0.210 & $0.000-6.567$ & 0.963 & 0.000 \\
\hline Resection (GTR) & 0.395 & $0.000-61.834$ & 0.971 & 0.000 \\
\hline Recurrence & 0.282 & $0.203-1.591$ & 0.348 & $0.136-2.022$ \\
\hline Pathology grade & 0.303 & $0.618-4.712$ & 0.898 & $0.335-3.478$ \\
\hline Radiation (Yes) & 0.215 & $0.681-5.533$ & 0.133 & $0.114-1.333$ \\
\hline
\end{tabular}

The median RFS of patients with grade II and III were 112 and 72 , respectively $(p=0.001)$. Pathological grade is the only prognostic factor for RFS by both the univariate $(p=0.003)$ and multivariate $(p=0.005)$ Cox regression analyses (Table 5).

\section{Discussion}

Intracranial HPC is a rare disease, and it is also rare in the literature for any single study having a large case number and a satisfactory length of follow-up. In our present report on 66 patients, some of our findings concur with the previously published results in the literature, but some do not. Impact of the extent of tumor resection have been examined by several studies, and complete tumor resection was shown to play a pivotal role for both local control and survival [7, 12-23]. In our study, however, GTR did not affect the treatment results. This may be explained by that $90 \%$ of our patients had GTR and thus making it difficult to detect a difference statistically when compared with the small number of patients with residual tumor.

Table 5 Univariate and Multivariate Analysis of Factors Associated with Recurrence-free Survival in Patients of Intracranial Hemangiopericytoma

\begin{tabular}{|c|c|c|c|c|}
\hline \multirow[t]{3}{*}{ Variable } & \multirow{2}{*}{\multicolumn{2}{|c|}{$\begin{array}{l}\text { Univariate Analysis } \\
\text { RFS }\end{array}$}} & \multirow{2}{*}{\multicolumn{2}{|c|}{$\begin{array}{l}\text { Multivariate Analysis } \\
\text { RFS }\end{array}$}} \\
\hline & & & & \\
\hline & $P$ & $95 \% \mathrm{Cl}$ & $p$ & $95 \% \mathrm{Cl}$ \\
\hline Age & 0.107 & $0.208-1.166$ & 0.083 & $0.173-1.114$ \\
\hline Sex & 0.231 & $0.248-1.400$ & 0.302 & $0.229-1.580$ \\
\hline Location & 0.787 & $0.293-2.538$ & 0.518 & $0.175-2.409$ \\
\hline Resection (GTR) & 0.103 & $0.832-7.404$ & 0.238 & $0.591-8.314$ \\
\hline Pathology grade & $0.003^{*}$ & $1.639-10.663$ & $0.005^{*}$ & $1.495-9.813$ \\
\hline Radiation (Yes) & 0.716 & $0.375-1.961$ & 0.781 & $0.463-2.783$ \\
\hline
\end{tabular}

Most studies investigating the effect of PORT in intracranial HPC were based on single-center analysis with a limited patient number, and the results were often contradictory. Meta-analyses and studies based on accumulated database have been conducted to overcome the problems of small case series, but their results were also inconsistent [24-26]. Although the role of PORT in the GTR patients is not clear, the general consensus is that PORT is beneficial for patients undergoing STR. Some studies found that PORT following STR improves both RFS and OS compared with STR alone [8, 25-28], and the others reported that PORT following GTR may also prolong OS $[24,26,28,29]$ or improve local control [22, 30]. Contrary to the above, some authors have reported that PORT after GTR has no impact on survival $[6,25$, 31] or that PORT should not be used except for patients with recurrences [32, 33]. In our study, we have found that PORT after surgery has no significant impact on the overall and disease-free survivals. This is in line with the results from Lee et al. who underwent an analysis of practice pattern in the US for intracranial HPC and the PORT effect on its survival. They obtained data of 588 cases from the cancer registry, of which 323 (54.9\%) received postoperative radiation. The 5 -year overall survival for those receiving PORT $77.1 \%$, not significantly different from the $83.8 \%$ for those who did not $(p=$ 0.14). Postoperative radiation was not prognostic for survival on multivariable analysis [34]. This observation was not altered after propensity score matching.

SRS has been used for the patients with residual or recurrent intracranial HPCs [18, 32, 35-39]. It was reported that postoperative SRS resulted in a better local tumor control in intracranial HPC patients [18]. In our subgroup analysis, patients with SRS had a similar OS to the patients with IMRT. The biologically effective dose (BED) of the SRS and IMRT groups for HPC with an $\alpha /$ $\beta$ ratio of $10 \mathrm{~Gy}$ was about $33.6-41.6 \mathrm{~Gy}_{10}$ and $72 \mathrm{~Gy}_{10}$, respectively. The biological effectiveness of the IMRT technique was much higher than the SRS method, yet resulting in no higher local control. The reason is not clear why a higher BED did not result in a higher local effect. However, considering that SRS may be able to minimize the radiation to the adjacent tissues due to the high-precision delivery of radiation to HPC with a steep radiation dose gradient, it is a reasonable PORT option for HPC patients $[32,40]$. There is no consensus on the optimal radiation dose for single-fraction SRS for intracranial HPC. Some centers have reported an improved local control at higher tumor margin doses, ranging from 14 to 17 Gy [41, 42], but other studies using tumor margin doses exceeding $20 \mathrm{~Gy}$ did not show an improved local control [43, 44].

From our analysis, PORT does not seem to improve local control, RFS and overall survival. Yet caution in 
interpretating the present findings is needed due to the limitation of this study that includes the small sample size and its retrospective nature. To examine the exact impact of PORT on local control and survival and the different effects between IMRT and SRS as a PORT option requires a multi-center randomized trial with a larger sample size.

\section{Conclusion}

Before the arrival of more convincing data from a randomized trial, we have to rely on results from suboptimal studies like this retrospective analysis, with prudent judgement. Although PORT did not improve the local control rates nor the survivals in this retrospective analysis, in view of the limitations of the present report and the existing conflicting results, PORT may still be considered in HPC. The finding that local control rates after IMRT and SRS were similar suggests that both radiotherapy techniques are viable options.

\section{Abbreviations}

IMRT: Intensity-modulated radiotherapy; SRS: Stereotactic radiosurgery; OS: Overall survival; RFS: Recurrence-free survival; PORT: Post-operative radiotherapy; HPC: Hemangiopericytoma; WHO: World Health Organization; EBRT: External beam radiotherapy; GTR: Gross tumor resection; STR: Subtotal tumor resection; CTV: Clinical target volume; H\&E: Hematoxylin \& Eosin; IHC: Immunohistochemical

\section{Acknowledgements}

We thank Hong-ji Wu for the assistance with data analysis.

\section{Authors' contributions}

$J X$ designed, collected and analyzed clinical data, and wrote the manuscript. YD, LX, WW, FC, XW, YZ, QZ, FZ, JL, LL assisted with collection and analysis of data. YJ masterminded and supervised the design and conduction of the research, and the interpretation of the results, and writing of the manuscript. LL provided the funding and co-supervised the conduction of the study. All authors have read and approved the manuscript.

\section{Funding}

This study was funded by National Natural Science Foundation of China (No. 81872041, 81672821, 81872470).

\section{Availability of data and materials}

The datasets of the study are available on request to the correspondent authors.

\section{Declarations}

\section{Ethics approval and consent to participate}

The study protocol was approved by the hospital review boards of the participant hospitals with a waiver of informed consent of the individual patients. The study was approved by Nanfang Hospital ethics commits, Shandong Provincial Hospital ethics commits, General Hospital of Southern Theater Command ethics commits, Chenzhou No.1 People's Hospital ethics commits, Zhujiang Hospital ethics commits. The ethics number is 2019055. The study was conducted in accordance with the ethical standards of the institutional and national research committees and with the 1964 Helsinki declaration and its later amendments of comparable ethical standards.

\section{Consent for publication}

Not Applicable.

\section{Competing interests}

All the authors declare no conflict of interest.

\section{Author details}

'Department of Pathology, Nanfang Hospital and School of Basic Medical Science, Southern Medical University, 1838, Guangzhoudadao Rd, Guangzhou, Guangdong Province 510515, People's Republic of China. ${ }^{2}$ Guangdong Province Key Laboratory of Molecular Tumor Pathology, Guangzhou 510515, Guangdong Province, People's Republic of China. ${ }^{3}$ Department of Hand and Foot Surgery, Shandong Provincial Hospital Affiliated to Shandong First Medical University, Jinan, China. ${ }^{4}$ Department of Radiation Oncology, Nanfang Hospital, Southern Medical University, Guangzhou, Guangdong Province, China. ${ }^{5}$ Department of Pathology, General Hospital of Southern Theater Command, People's Liberation Army of China, Guangzhou, China. 'Radiotherapy Center, Chenzhou No.1 People's Hospital, Chenzhou, Hunan Province, China. 'Department of Pathology, Zhujiang Hospital, Southern Medical University, Guangzhou, Guangdong Province, People's Republic of China. ${ }^{8}$ Department of Radiotherapy, Shanghai Concord Medical Cancer Center, Shanghai, China. ${ }^{9}$ Department of Obstetrics and Gynecology, General Hospital of Southern Theater Command, People's Liberation Army of China, Guangzhou, China. ${ }^{10}$ Department of Radiation Oncology, Yee Zen General Hospital, 30, Yangxing North Rd, Yang Mei District, Tao Yuan City, Taiwan.

Received: 14 June 2020 Accepted: 6 July 2021

Published online: 12 August 2021

\section{References}

1. Arthur PS, Margaret RM. Hemangiopericytoma: a vascular tumor featuring zimmermann's pericytes. Ann Surg. 1942;116:26-33.

2. Jo VY, Fletcher CDM. WHO classification of soft tissue tumours: an update based on the 2013 (4th) edition. Pathology. 2014 Feb;46(2):95-104. https:// doi.org/10.1097/PAT.0000000000000050.

3. Begg CF, Garret R. Hemangiopericytoma occurring in the meninges: case report. Cancer. 1954;7(3):602-6. https://doi.org/10.1002/1097-0142(1954 05)7:3<602::AID-CNCR2820070319>3.0.CO;2-A.

4. Cushing $\mathrm{H}$, Eisenhardt L. Meningiomas: their classification regional behaviour life history and surgical results. Arch NeurPsych. 1939;41(3):657-8.

5. Bonde VR, Goel A. Two patients with intracavernous hemangiopericytoma. J Clin Neurosci. 2009;16(2):330-3. https://doi.org/10.1016/j.jocn.2008.01.019.

6. Louis DN, Ohgaki H, Wiestler OD, Cavenee WK, Burger PC, Jouvet A, et al. The 2007 WHO classification of tumours of the central nervous system. Acta Neuropathol. 2007;114(2):97-109. https://doi.org/10.1007/s00401-007-0243-4.

7. Rutkowski MJ, Jian BJ, Bloch O, Chen C, Sughrue ME, Tihan T, et al. Intracranial hemangiopericytoma: clinical experience and treatment considerations in a modern series of 40 adult patients. Cancer. 2012;118(6): 1628-36. https://doi.org/10.1002/cncr.26411.

8. Melone AG, D'Elia A, Santoro F, et al. Intracranial Hemangiopericytoma -our experience in 30 years: a series of 43 cases and review of the literature. World Neurosurg. 2014;81(3-4):556-62. https://doi.org/10.1016/j.wneu.2 013.11.009.

9. Guthrie BL, Ebersold MJ, Scheithauer BW, Shaw EG. Hemangiopericytoma -the role of radiotherapy, treatment, and long-term follow-up of 44 cases. Neurosurgery. 1989;25(4):514-22. https://doi.org/10.1227/00006123-19891 0000-00003.

10. Jellinger K, Slowik F. Histological subtypes and prognostic problems in meningiomas. J Neurol. 1975;208(4):279-98. https://doi.org/10.1007/ BF00312803.

11. Kleihues P, Burger PC, Scheithauer BW. World Health Organization International Histological Classification of Tu mours: histological typing of tumours of the central nervous system. Berlin Heidelberg New York Tokyo: Springer; 1991. p. 38.

12. Kleihues $\mathrm{P}$, Louis $\mathrm{DN}$, Scheithauer BW, et al. The $\mathrm{WHO}$ classification of tumors of the nervous system. J Neuropathol Exp Neurol. 2002;61(3):215-25, discussion 226-9. https://doi.org/10.1093/jnen/61.3.215.

13. Alen JF, Lobato RD, Gomez PA, et al. Intracranial Hemangiopericytoma: study of 12 cases. Acta Neurochir. 2001;143:575-86.

14. Wang W, Zhang GJ, Zhang LW, Li D, WU Z, Zhang JT. Long-term outcome and prognostic factors after repeated surgeries for intracranial Hemangiopericytomas. World Neurosurg. 2017;107:495-505. https://doi. org/10.1016/j.wneu.2017.08.027.

15. Sheehan J, Kondziolka D, Flickinger J, et al. Radiosurgery for treatment of recurrent intracranial hemangiopericytomas. Neurosurgery. 2002;51:905-11. 
16. Kim YJ, Park JH, Kim Yl, Jeun SS. Treatment strategy of intracranial Hemangiopericytoma. Brain Tumor Res Treat. 2015;3(2):68-74. https://doi. org/10.14791/btrt.2015.3.2.68

17. Jellinger K, Paulus W, Slowik F. The enigma of meningeal hemangiopericytoma. Brain Tumor Pathol. 1991;8:33-43.

18. Kano H, Niranjan A, Kondziolka D. Adjuvant stereotactic radiosurgery after resection of intracranial hemangiopericytomas. Int J Radiat Oncol Biol Phys. 2008;72(5):1333-9. https://doi.org/10.1016/j.jirobp.2008.03.024.

19. Dufour $H$, Métellus $P$, Fuentes $S$, et al. Meningeal hemangiopericytoma: a retrospective study of 21 patients with special review of postoperative external radiotherapy. Neurosurgery. 2001;48:756-62.

20. Fountas KN, Kapsalaki E, Kassam M, Feltes CH, Dimopoulos VG, Robinson JS, et al. Management of intracranial meningeal hemangiopericytomas: outcome and experience. Neurosurg Rev. 2006;29(2):145-53. https://doi. org/10.1007/s10143-005-0001-9.

21. Heiser MA, Waldron JS, Tihan T, Parsa AT, Cheung SW. Temporal fossa hemangiopericytoma: a case series. Otol Neurotol. 2009;30(7):985-9. https:// doi.org/10.1097/MAO.0b013e3181b76b58.

22. Kim JH, Jung HW, Kim YS, Kim CJ, Hwang SK, Paek SH, et al. Meningeal hemangiopericytomas: long-term outcome and biological behavior. Surg Neurol. 2003;59(1):47-53. https://doi.org/10.1016/S0090-3019(02)00917-5.

23. Kumar N, Kumar R, Kapoor R, et al. Intracranial meningeal hemangiopericytoma: 10 years experiences of a tertiary care institute. Acta Neurochir. 2012;15:1647-51.

24. Sonabend AM, Zacharia BE, Goldstein H, Bruce SS, Hershman D, Neugut Al et al. The role for adjuvant radiotherapy in the treatment of hemangiopericytoma: a surveillance, epidemiology, and end results analysis. J Neurosurg. 2014;120(2):300-8. https://doi.org/10.3171/2013.10.JNS13113.

25. Ghia AJ, Allen PK, Mahajan A, Penas-Prado M, McCutcheon IE, Brown PD. Intracranial hemangiopericytoma and the role of radiation therapy: a population based analysis. Neurosurgery. 2013;72(2):203-9. https://doi.org/1 0.1227/NEU.0b013e31827b9e68.

26. Stessin AM, Sison C, Nieto J, Raifu M, Li B. The role of postoperative radiation therapy in the treatment of meningeal hemangiopericytomaexperience from the SEER database. Int J Radiat Oncol Biol Phys. 2013;85(3): 784-90. https://doi.org/10.1016/j.jirobp.2012.05.042.

27. Staples JJ, Robinson RA, Wen BC, Hussey DH. Hemangiopericytoma--the role of radiotherapy. Int J Radiat Oncol Biol Phys. 1990;19(2):445-51. https://doi. org/10.1016/0360-3016(90)90556-Y.

28. Schiariti M, Goetz P, El-Maghraby H, et al. Hemangiopericytoma: long-term outcome revisited. J Neurosurg. 2011;114(3):747-55. https://doi.org/10.31 71/2010.6.JNS091660.

29. Soyuer S, Chang EL, Selek U, McCutcheon IE, Maor MH. Intracranial meningeal hemangiopericytoma: the role of radiotherapy: report of 29 cases and review of the literature. Cancer. 2004;100(7):1491-7. https://doi. org/10.1002/cncr.20109.

30. Ghia AJ, Chang EL, Allen PK, Mahajan A, Penas-Prado M, McCutcheon IE, et al. Intracranial hemangiopericytoma: patterns of failure and the role of radiation therapy. Neurosurgery. 2013;73(4):624-30. https://doi.org/10.1227/ NEU.0000000000000064.

31. Rutkowski MJ, Sughrue ME, Kane AJ, Aranda D, Mills SA, Barani IJ, et al. Predictors of mortality following treatment of intracranial hemangiopericytoma. J Neurosurg. 2010;113(2):333-9. https://doi.org/10.31 71/2010.3.JNS091882.

32. Olson C, Yen CP, Schlesinger D, Sheehan J. Radiosurgery for intracranial hemangiopericytomas: outcomes after initial and repeat gamma knife surgery. J Neurosurg. 2010;112(1):133-9. https://doi.org/10.3171/2009.3.JNS0923.

33. Rutkowski MJ, Bloch O, Jian BJ, Chen C, Sughrue ME, Tihan T, et al. Management of recurrent intracranial hemangiopericytoma. J Clin Neurosci. 2011;18(11):1500-4. https://doi.org/10.1016/j.jocn.2011.04.009.

34. Lee A, Sidiqi B, Wang A, Safdieh J, Schreiber D. Patterns of care and outcomes of postoperative radiation for intracranial hemangiopericytoma in United States hospitals. Clin Neurol Neurosurg. 2018;167:1-5. https://doi. org/10.1016/j.clineuro.2018.02.004

35. Payne BR, Prasad D, Steiner M, Steiner L. Gamma surgery for hemangiopericytomas. Acta Neurochir. 2000;142(5):527-36. https://doi.org/1 $0.1007 / \mathrm{s} 007010050465$

36. Ecker RD, Marsh WR, Pollock BE, Kurtkaya-Yapicier Ö, McClelland R, Scheithauer BW, et al. Hemangiopericytoma in the central nervous system: treatment, pathological features, and long-term follow up in 38 patients. Neurosurg. 2003;98(6):1182-7. https://doi.org/10.3171/jns.2003.98.6.1182.
37. Sun S, Liu A, Wang C. Gamma knife radiosurgery for recurrent and residual meningeal hemangiopericytomas. Stereotact Funct Neurosurg. 2009;87(2): 114-9. https://doi.org/10.1159/000202978.

38. Or Cl, Lee CC, Seyed HM, et al. Stereotactic radiosurgery for intracranial hemangiopericytomas: a multicenter study. J Neurosurg. 2017;126:744-54.

39. Jin WK, Dong GK, Chung HT, et al. Gamma knife stereotactic radiosurgery for intracranial hemangiopericytomas. J Neuro-Oncol. 2010;99:115-22.

40. Ganz JC. Rare tumours and other lesions. In: Ganz JC, editor. Gamma knife neurosurgery. Wien: Springer; 2011. p. 349-52. https://doi.org/10.1007/ 978-3-7091-0343-2_22.

41. Kano H, Niranjan A, Kondziolka D, Flickinger JC, Lunsford LD. Adjuvant stereotactic radiosurgery after resection of intracranial hemangiopericytomas. Int J Radiat Oncol Biol Phys. 2008;72(5):1333-9. https://doi.org/10.1016/j.jijobp.2008.03.024.

42. Kim JW, Kim DG, Chung HT, Paek SH, Kim YH, Han JH, et al. Gamma knife stereotactic radiosurgery for intracranial hemangiopericytomas. J NeuroOncol. 2010;99(1):115-22. https://doi.org/10.1007/s11060-010-0114-z.

43. Chang SD, Sakamoto GT. The role of radiosurgery for hemangiopericytomas. Neurosurg Focus. 2005;14(5):14

44. Veeravagu A, Jiang B, Patil CG, Lee M, Soltys SG, Gibbs IC, et al. Cyber knife stereotactic radiosurgery for recurrent, metastatic, and residual hemangiopericytomas. J Hematol Oncol. 2011;4(1):26. https://doi.org/10.11 86/1756-8722-4-26.

\section{Publisher's Note}

Springer Nature remains neutral with regard to jurisdictional claims in published maps and institutional affiliations.
Ready to submit your research? Choose BMC and benefit from:

- fast, convenient online submission

- thorough peer review by experienced researchers in your field

- rapid publication on acceptance

- support for research data, including large and complex data types

- gold Open Access which fosters wider collaboration and increased citations

- maximum visibility for your research: over $100 \mathrm{M}$ website views per year

At $\mathrm{BMC}$, research is always in progress.

Learn more biomedcentral.com/submissions 